\title{
The interaction between lithium acceptors and gallium donors in zinc oxide
}

Cite as: J. Appl. Phys. 124, 245702 (2018); https://doi.org/10.1063/1.5063326

Submitted: 26 September 2018 . Accepted: 06 December 2018 . Published Online: 26 December 2018

T. N. Sky, K. M. Johansen (D), Y. K. Frodason, B. G. Svensson, and L. Vines
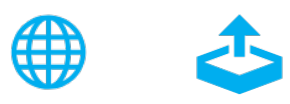

Export Citation

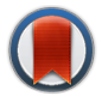

View Online

CrossMark

\section{ARTICLES YOU MAY BE INTERESTED IN}

Ultrafast electron hole plasma dynamics in chemically pristine and Ag-doped ZnO nanorods Journal of Applied Physics 124, 243103 (2018); https://doi.org/10.1063/1.5058121

Geometric structure and electronic properties of wurtzite $\mathrm{GaN} / \mathrm{HfO}_{2}$ interface: A firstprinciples study

Journal of Applied Physics 124, 245703 (2018); https://doi.org/10.1063/1.5048946

First-principles characterization of native-defect-related optical transitions in ZnO Journal of Applied Physics 122, 035704 (2017); https://doi.org/10.1063/1.4992128 


\title{
The interaction between lithium acceptors and gallium donors in zinc oxide
}

\author{
T. N. Sky, ${ }^{\text {a) }}$ K. M. Johansen, Y. K. Frodason, B. G. Svensson, and L. Vines \\ Department of Physics/Center for Materials Science and Nanotechnology, University of Oslo, P.O. Box 1048 \\ Blindern, N-0316 Oslo, Norway
}

(Received 26 September 2018; accepted 6 December 2018; published online 26 December 2018)

\begin{abstract}
Diffusion of lithium $(\mathrm{Li})$ in uniformly gallium $(\mathrm{Ga})$-doped monocrystalline bulk zinc oxide $(\mathrm{ZnO})$ is studied over a wide temperature range $\left(500-1150^{\circ} \mathrm{C}\right)$ and is demonstrated to be dictated by the distribution of Ga. Below $800^{\circ} \mathrm{C}$, the indiffusion of $\mathrm{Li}$ from a Li-doped $\mathrm{ZnO}$ sputtered film into $n^{+}$ single crystalline $\mathrm{ZnO}$ yields an abrupt and compensated Li-doped box region with the Li concentration matching the free-electron concentration, in accordance with several previous experimental and theoretical reports. However, experimental observations of Li-diffusion at higher temperatures reveal a dissociative diffusion mechanism for heat treatments up to $1150^{\circ} \mathrm{C}$. By employing a reaction-diffusion model that includes both $\mathrm{Li}$ and $\mathrm{Ga}$, a dissociation energy of $4.6 \mathrm{eV}$ is obtained from the experimental $\mathrm{Li}$ diffusion data. This is in excellent agreement with theoretical results for the dissociation of $\left(\mathrm{Li}_{\mathrm{Zn}} \mathrm{Ga}_{\mathrm{Zn}}\right)^{0}(4.8 \mathrm{eV})$ into $\mathrm{Li}_{i}^{+}$and $\left(\mathrm{Ga}_{\mathrm{Zn}} \mathrm{V}_{\mathrm{Zn}}\right)^{-}$and suggests that this neutral and stable acceptor-donor pair prevails in Li- and Ga-doped $\mathrm{ZnO}$. Published by AIP Publishing.

https://doi.org/10.1063/1.5063326
\end{abstract}

\section{INTRODUCTION}

The behavior of lithium (Li) in crystalline zinc oxide $(\mathrm{ZnO})$ has been studied for many decades, with the first report on experimental Li diffusion as early as $1960 .{ }^{1}$ Both donor and acceptor properties of $\mathrm{Li}$ were observed early on and it was suggested that $\mathrm{Li}$ substituting $\mathrm{Zn}\left(\mathrm{Li}_{\mathrm{Zn}}{ }^{-}\right)$and interstitial $\mathrm{Li}\left(\mathrm{Li}_{i}^{+}\right)$was the identity of the acceptor and donor states, respectively. ${ }^{1}$ This amphoteric behavior of $\mathrm{Li}$ is now well established based on more recent experimental ${ }^{2-4}$ and theoretical ${ }^{5,6}$ results. Li has been shown to primarily reside on the $\mathrm{Zn}$ site in n-type $\mathrm{ZnO},{ }^{4}$ demonstrating the selfcompensating effect of $\mathrm{Li}$, with $\mathrm{Li}_{\mathrm{Zn}}{ }^{-}$being favorable when the Fermi level $\left(\epsilon_{F}\right)$ is close to the conduction band minimum (CBM) and under oxygen rich conditions, while $\mathrm{Li}_{i}^{+}$would prevail for $\epsilon_{F}$ close to the valence band maximum (VBM) and under Zn-rich conditions.

$\mathrm{Li}$ diffusion in $\mathrm{ZnO}$ has previously been studied at temperatures up to $600^{\circ} \mathrm{C}$ by Lander ${ }^{1}$ and Knutsen et al. ${ }^{7}$ under Zn-rich and O-rich conditions, respectively. In both reports, the diffusion of $\mathrm{Li}$ was described by assuming $\mathrm{Li}_{i}^{+}$to be the mobile species, while $\mathrm{Li}_{\mathrm{Zn}}{ }^{-}$was considered immobile in the studied temperature range. The model assumed a kick-out mechanism between substitutional $\mathrm{Zn}$ by mobile $\mathrm{Li}_{i}^{+}$into stable $\mathrm{Li}_{\mathrm{Zn}}{ }^{-}$and highly mobile $\mathrm{Zn}_{i}^{2+}$ (the migration barrier of $0.55 \mathrm{eV}^{8}$ ), with extracted $\mathrm{Li}_{i}^{+}$migration barriers of $0.98 \mathrm{eV}^{1}$ and $1.34 \mathrm{eV}^{7}$ reported for the two studies, respectively.

Theoretical results by Carvalho et al. ${ }^{6}$ using hybrid functional calculations reported an ionization energy of $0.6-1.1 \mathrm{eV}$ for $\mathrm{Li}_{\mathrm{Zn}}{ }^{-}$, while a migration barrier of $0.6-0.7 \mathrm{eV}$ for the diffusion of $\mathrm{Li}_{i}^{+}$was found. In addition, they further suggested that under O-rich conditions, the dominant diffusion process corresponds to a dissociative mechanism requiring a substantial activation energy. However, such a diffusion

a)t.n.sky@fys.uio.no mechanism would be observed at higher temperatures than that previously reported.

In this work, we have used secondary ion mass spectrometry (SIMS) and hybrid density functional theory (DFT) to study the diffusion of Li into the single crystal Ga-doped bulk $\mathrm{ZnO}$ containing very low residual $\mathrm{Li}$ concentration in the as-grown state. The background concentration of $\mathrm{Ga}$ donors made it possible to investigate the diffusion of $\mathrm{Li}$ at Fermi-level positions close to CBM, i.e., wherein the interstitial configuration is expected to be highly unfavorable. Unlike previously reported experiments on $\mathrm{Li}$ diffusion in $\mathrm{ZnO}$, the present study addresses the diffusion mechanisms of $\mathrm{Li}$ diffusion in the temperature range of $850-1150{ }^{\circ} \mathrm{C}$, evidencing a dissociative mechanism that has not previously been shown experimentally. The results demonstrate that the diffusion of $\mathrm{Li}$ is controlled by the concentration and distribution of $\mathrm{Ga}$, resulting in a close to one-to-one ratio between the $\mathrm{Li}$ and $\mathrm{Ga}$ concentrations at moderate temperatures. Combining the experimental SIMS results with hybrid DFT results using a reaction-diffusion type model,,${ }^{9,10}$ the diffusion of $\mathrm{Li}$ is evidenced to proceed by a dissociative donorvacancy assisted diffusion mechanism, where mobile $\mathrm{Li}_{i}^{+}$ reacts with more stable $\left(\mathrm{Ga}_{\mathrm{Zn}} \mathrm{V}_{\mathrm{Zn}}\right)^{-}$pairs to produce neutral $\left(\mathrm{Li}_{\mathrm{Zn}} \mathrm{Ga}_{\mathrm{Zn}}\right)^{0}$ pairs. A dissociation energy barrier of $4.6 \mathrm{eV}$ is extracted in the modelling of the experimental data, which is in excellent agreement with the theoretical predictions of $4.8 \mathrm{eV}$ for the dissociation of $\left(\mathrm{Li}_{\mathrm{Zn}} \mathrm{Ga}_{\mathrm{Zn}}\right)^{0}$.

\section{METHODS}

\section{A. Experimental}

A thin film of Li-doped $\mathrm{ZnO}\left(\sim 2 \times 10^{20} \mathrm{~cm}^{-3}\right)$ was deposited onto a hydrothermally grown single crystalline (0001-oriented) bulk $\mathrm{ZnO}$ wafer, containing an as-grown uniform Ga concentration of $1 \times 10^{19} \mathrm{~cm}^{-3}$ with a measured charge carrier concentration of $8 \times 10^{18} \mathrm{~cm}^{-3}$. The as-grown 
bulk wafers were obtained from the authors of Ref. 11, produced/grown using a modified hydrothermal method, resulting in a low residual $\mathrm{Li}$ concentration $\left(<1 \times 10^{15} \mathrm{~cm}^{-3}\right)$. The deposition of the Li-rich thin film was carried out in a Semicore magnetron sputtering system using a Li-doped $\mathrm{ZnO}$ target $\left(\mathrm{Zn}_{0.95} \mathrm{Li}_{0.05} \mathrm{O}\right)$ with a purity of $99.95 \%$, resulting in a $0.3 \mu \mathrm{m}$ thick Li-doped $\mathrm{ZnO}$ film. After the deposition, the wafer was cleaved into two smaller samples (labelled A and B) by the use of a Rofin PowerLine E-25 SHG laser cutter. Sample A was sequentially heat treated for $15 \mathrm{~min}$ from $500{ }^{\circ} \mathrm{C}$ up to $800^{\circ} \mathrm{C}$ in stages of $50{ }^{\circ} \mathrm{C}$, while sample $\mathrm{B}$ received a similar procedure but at higher temperatures $(850$ $1150^{\circ} \mathrm{C}$ ) and for longer times (30 min). A Cameca IMS7f Secondary Ion Mass Spectrometer (SIMS) equipped with a $\mathrm{O}_{2}$ primary ion beam source was used to record the concentration vs depth profiles of $\mathrm{Li}$ and $\mathrm{Ga}$. Absolute concentration values were obtained by measuring $\mathrm{Li}$ and $\mathrm{Ga}$ implanted reference samples, ensuring less than $\pm 10 \%$ error in accuracy. For depth calibration, the sputtered crater depths were determined by a Dektak 8 stylus profilometer and a constant erosion rate was assumed.

\section{B. Theoretical}

First-principles calculations were performed by using the Heyd-Scuseria-Ernzerhof (HSE) ${ }^{12}$ hybrid functional and the projector augmented wave method, ${ }^{13-15}$ as implemented in the VASP code. ${ }^{16,17}$ The fraction of the screened Hartree-Fock exchange was set to $\alpha=37.5 \%,{ }^{18}$ which yields a bandgap (3.42 eV) and lattice parameters $(a=3.244 \AA$ and $c=5.194 \AA$ ) that are in excellent agreement with experimental values. ${ }^{19,20}$ All defect calculations were performed using a plane-wave energy cutoff of $500 \mathrm{eV}$, a special $k$-point at $k=\left(\frac{1}{4}, \frac{1}{4}, \frac{1}{4}\right)$, and a 96-atom-sized wurtzite supercell. ${ }^{21}$ Defect formation energies were calculated by following the well established formalism outlined in Refs. 22 and 23. For instance, the formation energy of $\mathrm{Li}_{\mathrm{Zn}}$ in charge-state $q$ is given by

$$
E_{\mathrm{f}}\left(\mathrm{Li}_{\mathrm{Zn}}^{q}\right)=E_{\mathrm{tot}}\left(\mathrm{Li}_{\mathrm{Zn}}^{q}\right)-E_{\mathrm{tot}}^{\mathrm{bulk}}+\mu_{\mathrm{Zn}}-\mu_{\mathrm{Li}}+q \epsilon_{\mathrm{F}},
$$

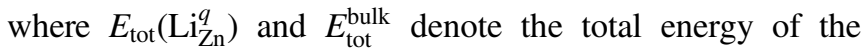
defect-containing and pristine supercells, and $\mu_{\mathrm{Zn}}$ and $\mu_{\mathrm{Li}}$ are the chemical potential of the removed $\mathrm{Zn}$ - and added Li-atom, respectively. For charged defects, we applied the anisotropic $^{24}$ Freysoldt-Neugebauer-Van de Walle finite-size correction. ${ }^{25,26}$ Oxygen rich conditions are considered, where $\mu_{\mathrm{Zn}}$ corresponds to the total energy per the bulk metallic $\mathrm{Zn}$ atom plus the formation enthalpy of $\mathrm{ZnO}$, i.e., $\mu_{\mathrm{Zn}}=E_{\mathrm{tot}}(\mathrm{Zn})+\Delta H_{\mathrm{f}}(\mathrm{ZnO})$. The solubility of $\mathrm{Li}$ is limited by the formation of $\mathrm{Li}_{2} \mathrm{O}$, and under oxygen rich conditions $\mu_{\mathrm{Li}}=E_{\mathrm{tot}}(\mathrm{Li})+\frac{1}{2} \Delta H_{\mathrm{f}}\left(\mathrm{Li}_{2} \mathrm{O}\right)$. Similarly, the solubility of $\mathrm{Ga}$ is limited by the formation of $\mathrm{Ga}_{2} \mathrm{O}_{3}$ and thus $\mu_{\mathrm{Ga}}=E_{\mathrm{tot}}(\mathrm{Ga})+\frac{1}{2} \Delta H_{\mathrm{f}}\left(\mathrm{Ga}_{2} \mathrm{O}_{3}\right)$.

\section{RESULTS AND DISCUSSION}

\section{A. Li diffusion at moderate temperatures}

Figure 1 shows the $\mathrm{Li}$ and Ga concentration vs depth profiles for the sample isocronally heat treated $(15 \mathrm{~min})$ at

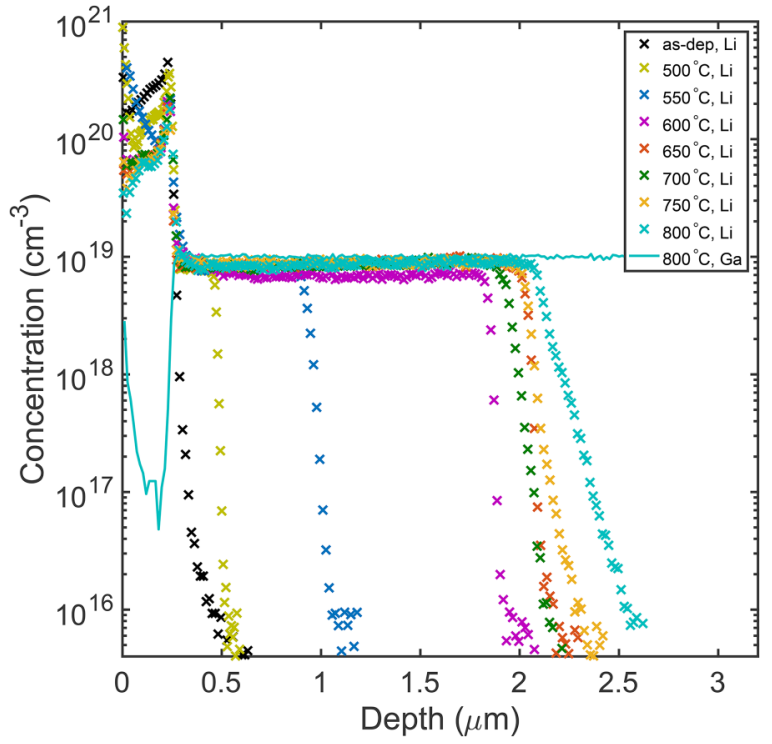

FIG. 1. Experimental Li and Ga concentration vs depth profiles of sample A isochronally heat treated $(15 \mathrm{~min})$ at temperatures $500-800^{\circ} \mathrm{C}$.

temperatures in the range $500-800^{\circ} \mathrm{C}$, as measured by SIMS. Already at $500^{\circ} \mathrm{C}, \mathrm{Li}$ starts to migrate from the $0.3 \mu \mathrm{m}$ thick Li-doped $\mathrm{ZnO}$ film into the Ga-doped $\mathrm{ZnO}$ bulk. At these temperatures, $\mathrm{Ga}$ is practically immobile (cf. Ref. 10) showing only a slight out-diffusion to the film at $800^{\circ} \mathrm{C}$. The concentration of $\mathrm{Li}$ in the plateau of the very distinct box-like Li diffusion profiles is about $8-9 \times 10^{18} \mathrm{~cm}^{-3}$ for all temperatures. Treatments up to $600{ }^{\circ} \mathrm{C}$ show a gradual increase in the effective diffusion length. However, at temperatures between $650{ }^{\circ} \mathrm{C}$ and $800{ }^{\circ} \mathrm{C}$, only a small increase in the effective diffusion length is observed, indicating a depletion of mobile $\mathrm{Li}$ in the film. Furthermore, above $700{ }^{\circ} \mathrm{C}$, a tail start to develop in the deep end of the Li boxprofiles, indicative of a different process emerging at higher temperatures. This unfortunately limits the possibility to extract reliable diffusion parameters. However, the general diffusion behavior of $\mathrm{Li}$ at moderate temperatures (Fig. 1) is in accordance with that observed in previous reports, ${ }^{1,7}$ where the diffusion of $\mathrm{Li}$ was explained to proceed by fast diffusing $\mathrm{Li}_{i}^{+}$, while $\mathrm{Li}_{\mathrm{Zn}}{ }^{-}$is practically immobile below $600^{\circ} \mathrm{C}$. In particular, it was found in Ref. 7 that the characteristic level at which the concentration of $\mathrm{Li}$ changes abruptly was correlated with the background concentration of ionized donors. Indeed, the experimental results presented in Fig. 1 strongly support this notion and further demonstrate that in the presence of a background doping of $\mathrm{Ga}$, the diffusion of Li follows the concentration and distribution of $\mathrm{Ga}$.

Experimental and theoretical studies of the amphoteric behavior of $\mathrm{Li}$ reported in the literature ${ }^{2-6}$ show that high doping levels of Li lead to a highly compensated material. Indeed, the Li-doped $\mathrm{ZnO}$ film is shown to be highly resistive by 4 -point probe measurements, with $\mathrm{Li}$ as the primary impurity. This suggests the presence of both $\mathrm{Li}_{\mathrm{Zn}}{ }^{-}$and $\mathrm{Li}_{i}^{+}$in the film. Mobile $\mathrm{Li}_{i}^{+}$will diffuse into the n-type bulk; however, $\mathrm{Li}_{i}^{+}$will be highly unfavorable and is expected to convert into a more energetically favorable configuration, e.g., the substitutional Zn-site, 
ensuring continued indiffusion from the film. Moreover, Fig. 1 suggests that $\mathrm{Li}$ is trapped by a defect stable up to $\sim 750^{\circ} \mathrm{C}$ after entering the bulk crystal, in good agreement with previous experiments. ${ }^{1,7}$

\section{B. Li diffusion above $800^{\circ} \mathrm{C}$}

Figure 2(a) shows the $\mathrm{Li}$ and $\mathrm{Ga}$ concentrations vs depth profiles for sample B after isochronal heat treatments (30 min) in the temperature range $850-1150{ }^{\circ} \mathrm{C}$. After the $850^{\circ} \mathrm{C}$ treatment, Li shows similar distinct box-like diffusion behavior as that observed for sample A above (Fig. 1). Note that the total amount of indiffused $\mathrm{Li}$ in sample $\mathrm{B}$ at $850^{\circ} \mathrm{C}$ is higher ( $\sim 1 \mu \mathrm{m}$ deeper profile) than that observed for sample $\mathrm{A}$ at the same temperature (Fig. 1). The reason for this difference may be attributed to an outdiffusion of $\mathrm{Li}$ from the deposited film due to a longer accumulated diffusion time in sample A compared to sample B. Nevertheless, this difference will not affect our analysis below. Increasing the temperature above $950^{\circ} \mathrm{C}$ clearly reveals that $\mathrm{Li}$ starts to redistribute, and the profiles extend over $20 \mu \mathrm{m}$ into the bulk after the $1150{ }^{\circ} \mathrm{C}$ treatment. As shown in Fig. 2(b), the integrated concentration of $\mathrm{Li}$ within the indiffused profiles is effectively maintained at all temperatures, demonstrating that no additional influx of $\mathrm{Li}$ occurs from the film (or the outflux from the bulk) after the initial $850^{\circ} \mathrm{C}$ treatment. This ensures a clear boundary condition, making it highly suitable to apply diffusion modelling.

Interestingly, the evolution of the Ga distribution within the initial indiffused box-region [Fig. 2(a)] shows a correlation to that of the $\mathrm{Li}$ distribution, or rather vice versa. The redistribution of $\mathrm{Ga}$ is observed for treatments exceeding $850^{\circ} \mathrm{C}$, in accordance with previous results ${ }^{10}$ reporting a migration barrier of $2.4 \mathrm{eV}$ for $\left(\mathrm{GaZn}_{\mathrm{Zn}}\right)^{-}$in $\mathrm{ZnO}$. In addition to the out diffusion of $\mathrm{Ga}$ causing a gradient in the $\mathrm{Ga}$ distribution toward the film, Ga also forms a distinct pattern at the interface between the $\mathrm{Li}$ doped and undoped bulk material. This is particularly prominent after the $950{ }^{\circ} \mathrm{C}$ and $1000{ }^{\circ} \mathrm{C}$ treatments [see the redistribution at $3-4 \mu \mathrm{m}$ shown in Fig. 2(c)], before it disappears again at higher temperatures. These features may be indicative of the presence of a considerable potential gradient across the Li-rich and Li-lean regions, as previously suggested for $\mathrm{Li}$-doped $\mathrm{ZnO}^{7}$

\section{Theoretical predictions of prevalent defects}

To get an overview of likely defect configurations that may be responsible for the initial $\mathrm{Li}$ "trapping" and subsequent apparent dissociation at higher temperatures, theoretical calculations using comparable conditions (oxygen-rich) were conducted. Figure 3(a) shows the formation energy vs the Fermi-level position $\left(\epsilon_{F}\right)$ for relevant defects, as obtained from hybrid DFT calculations. As can be seen, $\mathrm{Li}_{i}^{+}$is highly unfavorable under n-type conditions $\left(\epsilon_{F}\right.$ close to CBM) and will readily convert into any of the more energetically favorable configurations $\mathrm{Li}_{\mathrm{Zn}}{ }^{-}$or $\left(\mathrm{Li}_{\mathrm{Zn}} \mathrm{Ga}_{\mathrm{Zn}}\right)^{0}$, if encountering either $\mathrm{V}_{\mathrm{Zn}}{ }^{2-}$ or $\left(\mathrm{Ga}_{\mathrm{Zn}} \mathrm{V}_{\mathrm{Zn}}\right)^{-}$, respectively. The calculated stability of these substitutional Li-related defects is shown in Fig. 3(b), where the removal energy $E_{r}$ and dissociation energy $E_{d}$ of $\mathrm{Li}_{\mathrm{Zn}}{ }^{-}$and $\left(\mathrm{Li}_{\mathrm{Zn}} \mathrm{Ga}_{\mathrm{Zn}}\right)^{0}$ are given as a function of

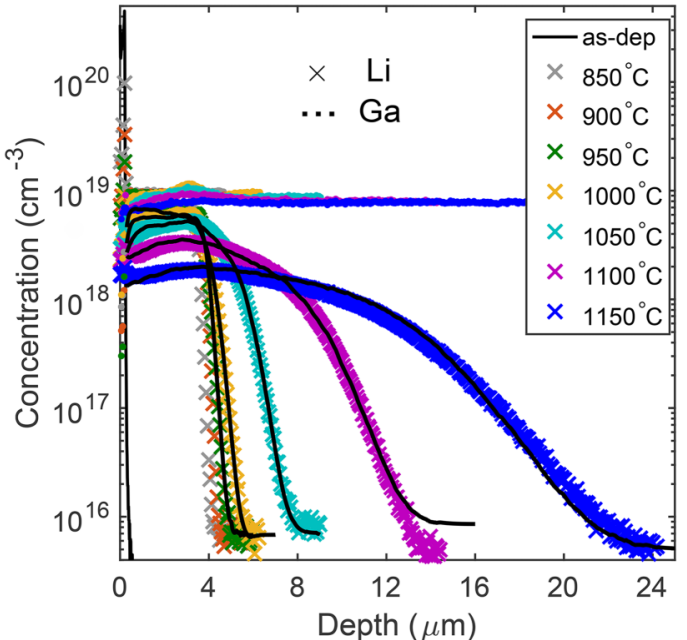

(a)

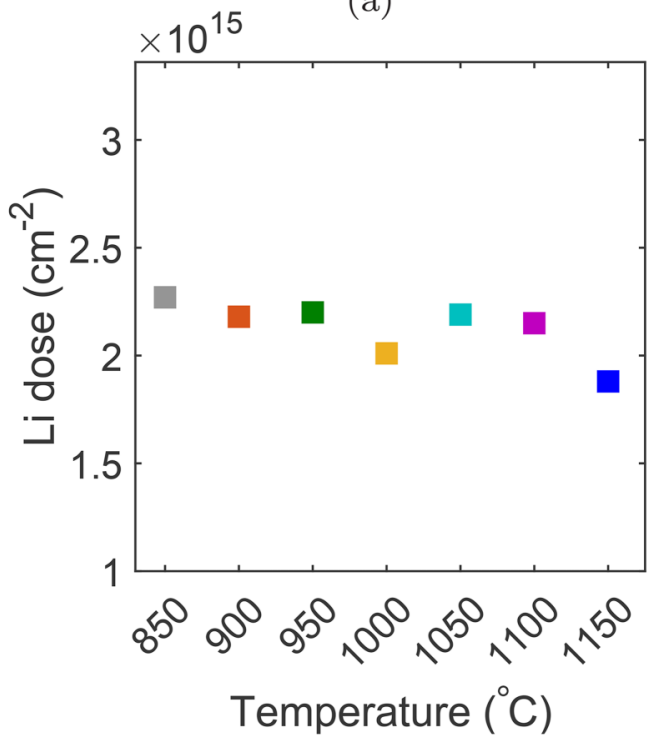

(b)

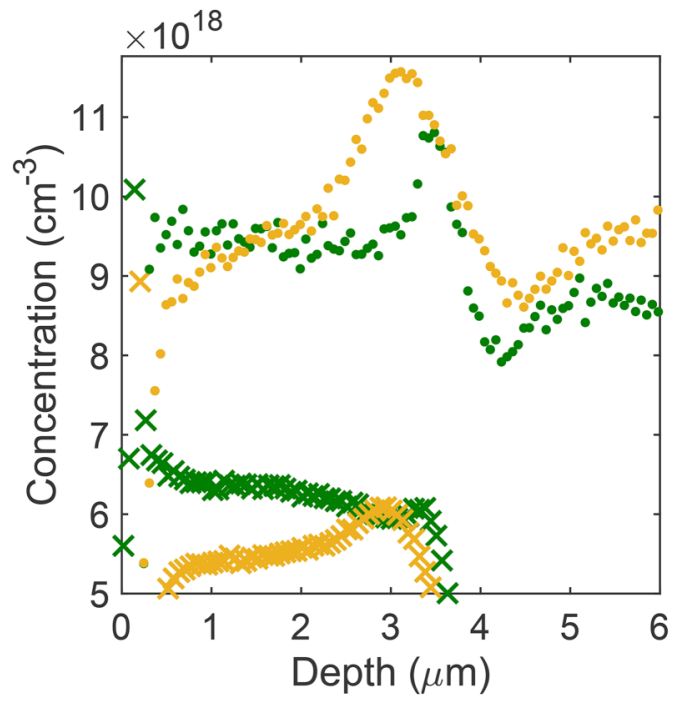

(c)

FIG. 2. (a) Experimental $\mathrm{Li}$ and $\mathrm{Ga}$ concentration vs depth profiles of sample B isochronally heat treated $(30 \mathrm{~min})$ at temperatures $850-1150{ }^{\circ} \mathrm{C}$. The solid lines show the best fit of the reaction-diffusion model [Eq. (2)]. The integrated Li concentration within the Li depth profiles is shown in (b), and (c) shows a zoomed view of the junction region for the 950 and $1000^{\circ} \mathrm{C}$ profiles (others excluded for clarity). 


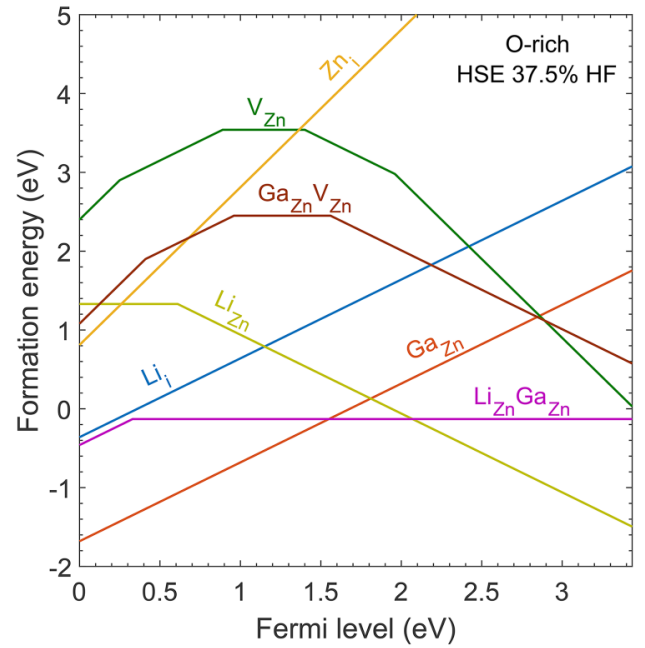

(a)

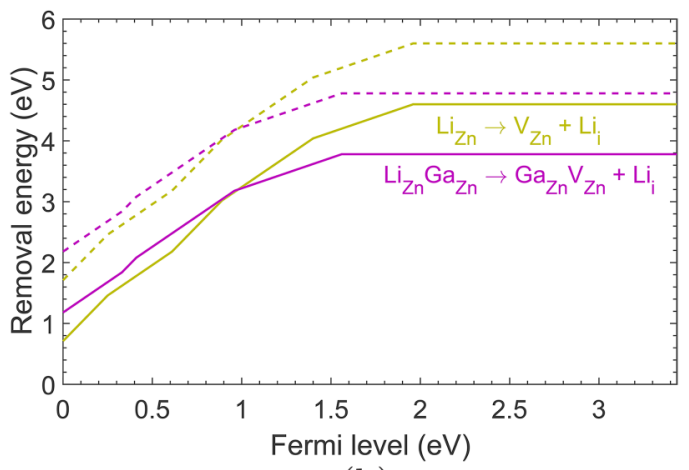

(b)

FIG. 3. (a) Predicted formation energies as a function of Fermi-level position for typical defects present in $\mathrm{Li}$ - and $\mathrm{Ga}$-doped $\mathrm{ZnO}$. (b) The resulting energy required to remove $\mathrm{Li}$ from the $\mathrm{Zn}$-site to the interstitial site, with or without $\mathrm{Ga}_{\mathrm{Zn}}{ }^{+}$as a next nearest neighbor, as represented by the solid lines. The dotted lines show the overall dissociation energy, which include the migration barrier of $\sim 1 \mathrm{eV}$ for the diffusion of $\mathrm{Li}_{i}^{+}$.

$\epsilon_{F}$. Here, $E_{r}$ is defined as the energy required to convert the substitutional $\mathrm{Li}$ to an interstitial position, but not completely dissociate, which also necessitates the inclusion of the smallest migration barrier for the involved constituents, i.e., the migration of either $\mathrm{Li}_{i}, \mathrm{~V}_{\mathrm{Zn}}$, or $\mathrm{Ga}_{\mathrm{Zn}} \mathrm{V}_{\mathrm{Zn}}$. From Fig. 3(b), $E_{r}\left(\mathrm{Li}_{\mathrm{Zn}}{ }^{-}\right)=4.6 \mathrm{eV}$ and $E_{r}\left[\left(\mathrm{Li}_{\mathrm{Zn}} \mathrm{Ga}_{\mathrm{Zn}}\right)^{0}\right]=3.8 \mathrm{eV}$ in the n-type $\mathrm{ZnO}$, with the respective $E_{d}$ being $\sim 1 \mathrm{eV}$ higher when considering the previously reported migration barrier of $\mathrm{Li}_{i}^{+}$ (see Ref. 1), provided that $\mathrm{Li}_{i}^{+}$leave behind the $\mathrm{V}_{\mathrm{Zn}}$-related defect. It is interesting to note that, at highly compensated conditions $\left(\epsilon_{F}\right.$ pinned close to mid-bandgap), $\left(\mathrm{Li}_{\mathrm{Zn}} \mathrm{Ga}_{\mathrm{Zn}}\right)^{0}$ is the most energetically favorable configuration. However, the dominating trap for $\mathrm{Li}_{i}^{+}$strongly depends on the availability of the isolated vacancy vs the donor-vacancy pair.

\section{Reaction diffusion model}

Motivated by the above indications of $\mathrm{V}_{\mathrm{Zn}}{ }^{2-}$ or $\left(\mathrm{Ga}_{\mathrm{Zn}} \mathrm{V}_{\mathrm{Zn}}\right)^{-}$being involved in the diffusion of $\mathrm{Li}$, the experimental diffusion data in Fig. 2(a) have been analyzed using a reaction-diffusion model ${ }^{9,10,27}$ assuming a dissociative diffusion mechanism. The diffusion of $\mathrm{Li}$ assisted by $\mathrm{V}_{\mathrm{Zn}}$-related defects $(X)$ can be described by reaction-diffusion equations (see, e.g., Refs. 9, 10, and 27-31 for a similar and general treatment)

$$
\begin{gathered}
\frac{\partial C_{X}}{\partial t}=K C_{V_{\mathrm{Zn}_{\mathrm{n}}} C_{\mathrm{Li}_{\mathrm{i}}}-v C_{X},} \\
\frac{\partial C_{\mathrm{Li}_{\mathrm{i}}}}{\partial t}=D_{\mathrm{Li}_{\mathrm{i}}} \frac{\partial^{2} C_{\mathrm{Li}_{\mathrm{i}}}}{\partial x^{2}}-\frac{\partial C_{X}}{\partial t},
\end{gathered}
$$

where $v=v_{0} e^{-E_{d}(X) / k_{B} T}$ is the dissociation rate for $X$ [i.e., either $\mathrm{Li}_{\mathrm{Zn}}{ }^{-}$or $\left.\left(\mathrm{Ga}_{\mathrm{Zn}} \mathrm{Li}_{\mathrm{Zn}}\right)^{0}\right]$, with $v_{0}$ being the attempt frequency (on the order of $\sim 10^{13} \mathrm{~s}^{-1}$ ) and $E_{d}(X)$ the activation energy for dissociation of $X$. In Eq. (2), the reaction constant $K=4 \pi R_{c} D_{\mathrm{Li}_{i}}$ is the formation rate of $X$, where $R_{c}$ is the coulomb force assisted effective reaction radius set to $1 \mathrm{~nm}$, and $D_{\mathrm{Li}_{i}}=2 \times 10^{-2} \exp \left(-0.98 \mathrm{eV} / k_{B} T\right) \mathrm{cm}^{2} \mathrm{~s}^{-1}$ is the diffusivity of interstitial $\mathrm{Li}$, as obtained by Lander, ${ }^{1}$ and is used as a fixed parameter in the simulations. In Eq. (2), it is assumed that the formation of $\mathrm{V}_{\mathrm{Zn}}{ }^{2-}$ is the limiting process for the formation of $\left(\mathrm{Ga}_{\mathrm{Zn}} \mathrm{V}_{\mathrm{Zn}}\right)^{-}$, i.e., $\left(\mathrm{Ga}_{\mathrm{Zn}} \mathrm{V}_{\mathrm{Zn}}\right)^{-}$forms instantaneously after the formation of $\mathrm{V}_{\mathrm{Zn}}{ }^{2-}$ at the studied temperatures, due to the high concentration of $\mathrm{Ga}_{\mathrm{Zn}}{ }^{+}$. Thus, the diffusion model is not sensitive to whether $\mathrm{Li}$ is captured by $\mathrm{V}_{\mathrm{Zn}}{ }^{2-}$ or $\left(\mathrm{Ga}_{\mathrm{Zn}} \mathrm{V}_{\mathrm{Zn}}\right)^{-}$. In the simulations, $C_{X}$ is determined from the preceding Li-profile with the integrated concentration of the Li being constant, as seen in Fig. 2(b). That is, the flux of $\mathrm{Li}_{i}$ at the interface is set to zero (except for the $1150^{\circ} \mathrm{C}$, where a slight outdiffusion has been considered).

In order to solve the above RD equations [Eq. (2)], a value for $C_{\mathrm{V}_{\mathrm{Zn}}}(x, t)$ is required. Profiles of $C_{\mathrm{V}_{\mathrm{Zn}}}(x, t)$ can be estimated from DFT estimates of the $\mathrm{V}_{\mathrm{Zn}}{ }^{2-}$ formation energy in Fig. 3(a). That is, the distribution of $\mathrm{V}_{\mathrm{Zn}}{ }^{2-}$ can be expressed as ${ }^{9,27}$

$$
C_{\mathrm{V}_{\mathrm{Zn}}}(x, t)=N_{s} e^{-\left[E_{f}\left(V_{\mathrm{Zn}}{ }^{2-}\right) / k_{B} T\right]}\left(\frac{n(x, t)}{N_{c}(T)}\right)^{2},
$$

where $N_{s}$ is the number of substitutional zinc lattice sites, $n=C_{\mathrm{Li}_{\mathrm{i}}}-2 C_{\mathrm{V}_{\mathrm{Zn}}}+C_{\mathrm{Gazn}_{\mathrm{z}}}$ accounts for the net charge carrier concentration of the system with $C_{\mathrm{Gazn}} \approx C_{\mathrm{Ga}}-C_{X}$, and $N_{c}$ is the effective density of states in the conduction band. This implies that an instantaneous equilibrium of $C_{\mathrm{V}_{\mathrm{Zn}}}$ is established and governed by $\epsilon_{F}$. The vacancy formation energy can then be expressed as $E_{f}\left(V_{\mathrm{Zn}}{ }^{2-}\right)=E_{f, 0}\left(V_{\mathrm{Zn}}{ }^{2-}\right)-2 \epsilon_{F}$, where $E_{f, 0}\left(V_{\mathrm{Zn}}{ }^{2-}\right)$ is the formation energy at the valence band edge, set to $6.9 \mathrm{eV}$ in our simulations as obtained from Fig. 3(a) and also guided by previous DFT reports. ${ }^{21,32-34}$ For a more detailed discussion of the reaction-diffusion model used in this work, see Refs. 9, 10, and 27

The considerations above leave only the dissociation rate $v$ as the unknown fitting variable to solve Eq. (2). Figure 4 shows the extracted $v$ vs the inverse absolute temperature, obtained from the best fits of the experimental data in Fig. 2(a). This results in a dissociation energy of $4.6 \pm 0.2 \mathrm{eV}$ with a prefactor of $v_{0}=5 \times 10^{15} \mathrm{~s}^{-1}$ for the diffusion of Li. Using the relation for Gibb's free energy $G=H-T S$, with an enthalpy $H$ and entropy $S$, the dissociation rate can be expressed as $v=v_{0} \mathrm{e}^{-G / k_{B} T}=\Gamma_{0} \mathrm{e}^{S / k_{B}} \mathrm{e}^{-H / k_{B} T}$, where $\Gamma_{0} \approx 10^{13} \mathrm{~s}^{-1}$ is the characteristic frequency of the lattice. Thus, the high value obtained for $v_{0}$ may suggest a contribution from the entropy (S) for the dissociation process. In this 


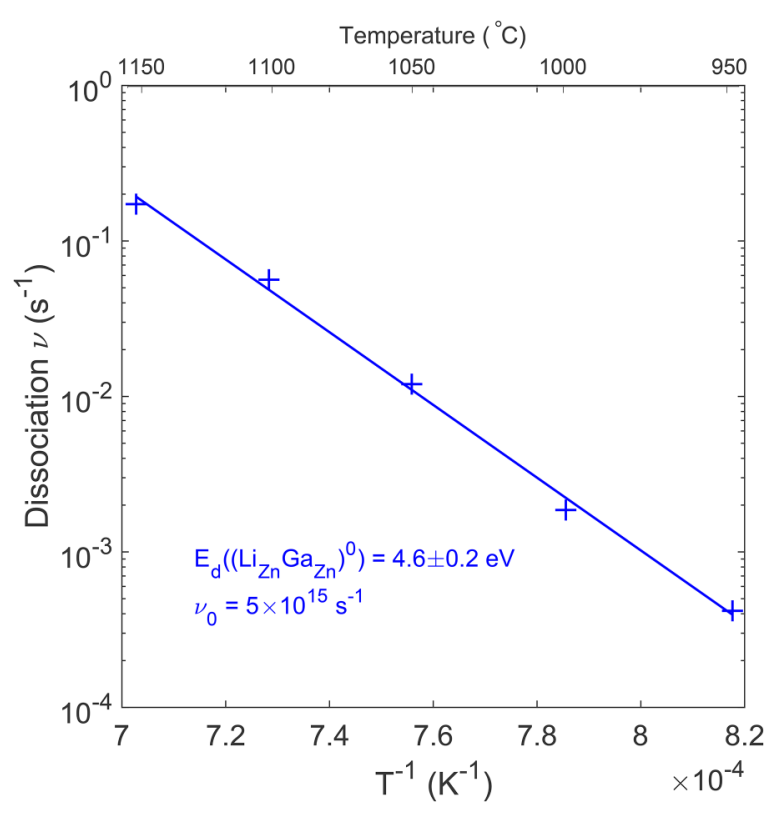

FIG. 4. Dissociation frequencies $v_{\mathrm{Li}_{\mathrm{Zn}} \mathrm{Ga} \mathrm{Zn}}$, as a function of the inverse absolute temperature.

regard, previous experimental studies of Ga-doped $\mathrm{ZnO}^{27,35}$ show that Ga-doping strongly enhances the $\mathrm{Zn}$ self-diffusion in $\mathrm{ZnO}$ and, in particular, that the diffusion prefactor scales with the Ga-concentration. These results, supported by the present study, indicate that the presence of $\mathrm{Ga}$ in the $\mathrm{ZnO}$ lattice affects the vibrational entropy, thus enhancing the diffusivity of both intrinsic- and impurity related defects. It can also be mentioned that theoretical studies of silicon carbide have previously shown that the entropy contribution for selfdiffusion is significant at high temperatures $\left(\sim 0.6 T_{m}\right.$, where $T_{m}$ is the melting temperature), ${ }^{36}$ suggesting that such effects may also be important for other material systems at comparable conditions.

By comparing the extracted value of $4.6 \pm 0.2 \mathrm{eV}$ (Fig. 4) with the DFT results in Fig. 3(b), this excludes the possibility that $\mathrm{Li}_{\mathrm{Zn}}{ }^{-}$is the dissociating defect, as this would imply a migration barrier for either $\mathrm{Li}_{i}$ or $\mathrm{V}_{\mathrm{Zn}}$ that is close to zero (i.e., the dissociation energy is the sum of the removal and migration barriers). On the other hand, this result is in excellent agreement with the sum of the migration barrier of $\mathrm{Li}_{i}^{+}$of $\sim 1 \mathrm{eV}$ and the energy barrier of $3.8 \mathrm{eV}$ as found from the DFT results in Fig. 3(b) for the removal of $\mathrm{Li}$ from $\left(\mathrm{Li}_{\mathrm{Zn}} \mathrm{Ga}_{\mathrm{Zn}}\right)^{0}$. Hence, we conclude that $\left(\mathrm{Li}_{\mathrm{Zn}} \mathrm{Ga}_{\mathrm{Zn}}\right)^{0}$ is the dominating Li-related defect in Li- and Ga-doped $\mathrm{ZnO}$.

\section{CONCLUSION}

Diffusion of $\mathrm{Li}$ in the single crystal Ga-doped $\mathrm{ZnO}$ is experimentally demonstrated to depend on the concentration and distribution of $\mathrm{Ga}$. Indiffusion of $\mathrm{Li}$ at temperatures from $500^{\circ} \mathrm{C}$ up to $800^{\circ} \mathrm{C}$ from a $\mathrm{Li}$-doped $\mathrm{ZnO}$ deposited film into $n^{+} \mathrm{ZnO}$ yields an abrupt and compensated Li-doped box region with a $\mathrm{Li}$ concentration matching the as-grown freeelectron concentration. The diffusion of $\mathrm{Li}$ is well described by employing a reaction-diffusion model that accounts for the presence of both $\mathrm{Li}$ and $\mathrm{Ga}$. Using previous experimental results ${ }^{1}$ for the $\mathrm{Li}_{i}^{+}$migration barrier, we obtain an activation energy of $4.6 \pm 0.2 \mathrm{eV}$ with a prefactor of $v_{0}=5 \times 10^{15} \mathrm{~s}^{-1}$ for the dissociation process mediating for the $\mathrm{Li}$ diffusion. This is in excellent agreement with our DFT results predicting an energy of $4.8 \mathrm{eV}$ for the dissociation of $\left(\mathrm{Li}_{\mathrm{Zn}} \mathrm{Ga}_{\mathrm{Zn}}\right)^{0}$ into $\mathrm{Li}_{i}^{+}$and $\left(\mathrm{Ga}_{\mathrm{Zn}} \mathrm{V}_{\mathrm{Zn}}\right)^{-}$, thus evidencing $\left(\mathrm{Li}_{\mathrm{Zn}} \mathrm{Ga}_{\mathrm{Zn}}\right)^{0}$ to be the assisting defect for the dissociative diffusion of $\mathrm{Li}$.

\section{ACKNOWLEDGMENTS}

We thank H. N. Riise for the growth of the sputterdeposited film. Financial support from the Research Council of Norway for funding of the FUNDAMENT (No. 151131, Fripro Toppforsk program), DYNAZOx-project (No. 221992), Salient (No. 239895), the University of Oslo, and the Norwegian Micro- and Nano-Fabrication Facility (No. NorFab 245963) are gratefully acknowledged.

${ }^{1}$ J. J. Lander, J. Phys. Chem. Solids 15, 324 (1960).

${ }^{2}$ P. T. Neuvonen, L. Vines, A. Y. Kuznetsov, B. G. Svensson, X. Du, F. Tuomisto, and A. Hallén, Appl. Phys. Lett. 95, 242111 (2009).

${ }^{3}$ L. Vines, E. V. Monakhov, R. Schifano, W. Mtangi, F. D. Auret, and B. G. Svensson, J. Appl. Phys. 107, 103707 (2010).

${ }^{4}$ K. M. Johansen, A. Zubiaga, I. Makkonen, F. Tuomisto, P. T. Neuvonen, K. E. Knutsen, E. V. Monakhov, A. Y. Kuznetsov, and B. G. Svensson, Phys. Rev. B 83, 245208 (2011).

${ }^{5}$ M. G. Wardle, J. P. Goss, and P. R. Briddon, Phys. Rev. B 71, 155205 (2005).

${ }^{6}$ A. Carvalho, A. Alkauskas, A. Pasquarello, A. K. Tagantsev, and N. Setter, Phys. Rev. B 80, 195205 (2009).

${ }^{7}$ K. E. Knutsen, K. M. Johansen, P. T. Neuvonen, B. G. Svensson, and A. Y. Kuznetsov, J. Appl. Phys. 113, 023702 (2013).

${ }^{8}$ D. G. Thomas, J. Phys. Chem. Solids 3, 229 (1957).

${ }^{9}$ K. M. Johansen, L. Vines, T. S. Bjorheim, R. Schifano, and B. G. Svensson, Phys. Rev. Appl. 3, 024003 (2015).

${ }^{10}$ T. N. Sky, K. M. Johansen, H. N. Riise, B. G. Svensson, and L. Vines, J. Appl. Phys. 123, 055701 (2018).

${ }^{11}$ W. Lin, K. Ding, Z. Lin, J. Zhang, J. Huang, and F. Huang, CrystEngComm 13, 3338 (2011).

${ }^{12}$ A. V. Krukau, O. A. Vydrov, A. F. Izmaylov, and G. E. Scuseria, J. Chem. Phys. 125, 224106 (2006).

${ }^{13}$ P. E. Blöchl, Phys. Rev. B 50, 17953 (1994).

${ }^{14}$ G. Kresse and J. Hafner, J. Phys. Condens. Matter 6, 8245 (1994).

${ }^{15} \mathrm{G}$. Kresse and D. Joubert, Phys. Rev. B 59, 1758 (1999).

${ }^{16}$ G. Kresse and J. Hafner, Phys. Rev. B 47, 558 (1993).

${ }^{17}$ G. Kresse and J. Furthmüller, Phys. Rev. B 54, 11169 (1996).

${ }^{18}$ F. Oba, A. Togo, I. Tanaka, J. Paier, and G. Kresse, Phys. Rev. B 77, 245202 (2008).

${ }^{19}$ D. C. Reynolds, D. C. Look, B. Jogai, C. W. Litton, G. Cantwell, and W. C. Harsch, Phys. Rev. B 60, 2340 (1999).

${ }^{20}$ J. Albertsson, S. C. Abrahams, and Å. Kvick, Acta Cryst. B 45, 34 (1989).

${ }^{21}$ Y. K. Frodason, K. M. Johansen, T. S. Bjørheim, B. G. Svensson, and A. Alkauskas, Phys. Rev. B 95, 094105 (2017).

${ }^{22}$ S. B. Zhang and J. E. Northrup, Phys. Rev. Lett. 67, 2339 (1991).

${ }^{23}$ C. Freysoldt, B. Grabowski, T. Hickel, J. Neugebauer, G. Kresse, A. Janotti, and C. G. Van de Walle, Rev. Mod. Phys. 86, 253 (2014).

${ }^{24}$ Y. Kumagai and F. Oba, Phys. Rev. B 89, 195205 (2014).

${ }^{25}$ C. Freysoldt, J. Neugebauer, and C. G. Van de Walle, Phys. Rev. Lett. 102, 016402 (2009).

${ }^{26}$ H.-P. Komsa, T. T. Rantala, and A. Pasquarello, Phys. Rev. B 86, 045112 (2012).

${ }^{27}$ T. N. Sky, K. M. Johansen, B. G. Svensson, and L. Vines, "Influence of Fermi level position on vacancy-assisted diffusion of aluminum in zinc oxide," Phys. Rev. B (to be published).

${ }^{28}$ E. Antoncik, Appl. Phys. A 56, 291 (1993).

${ }^{29} \mathrm{H}$. Bracht, Phys. Rev. B 75, 035210 (2007).

${ }^{30}$ M. Uematsu, J. Appl. Phys. 82, 2228 (1997).

${ }^{31}$ U. M. Gosele, Ann. Rev. Mater. Sci. 18, 257 (1988). 
${ }^{32}$ A. Janotti and C. G. Van de Walle, Phys. Rev. B 76, 165202 (2007).

${ }^{33}$ D. O. Demchenko, B. Earles, H. Y. Liu, V. Avrutin, N. Izyumskaya, Ü. Özgür, and H. Morkoç, Phys. Rev. B 84, 075201 (2011).

${ }^{34}$ D. Steiauf, J. L. Lyons, A. Janotti, and C. G. Van de Walle, APL Mater. 2, 096101 (2014).
${ }^{35}$ A. Azarov, V. Venkatachalapathy, Z. Mei, L. Liu, X. Du, A. Galeckas, E. Monakhov, B. G. Svensson, and A. Kuznetsov, Phys. Rev. B 94, 195208 (2016).

${ }^{36}$ E. Rauls, T. Frauenheim, A. Gali, and P. Deák, Phys. Rev. B 68, 155208 (2003). 